\title{
Prevalence of Maxillary Canine Impaction in Orthodontics At Eastern Riyadh Specialized Dental Center
}

\author{
Ahmed Ali Al Fawzan ${ }^{1}$,Moataz Alruwaithi ${ }^{2}$,Sultana Alsadoon ${ }^{3}$ \\ ${ }^{l}$ Orthodontic Demonstrator, College Of Dentistry, Qassim University, Ksa \\ ${ }^{2}$ Orthodontic Consultant, Eastern Riyadh Specialized Dental Center, Ksa \\ ${ }^{3}$ General Dentist, Armed Forces Hospital, Ksa
}

\begin{abstract}
Objective of this study is to highlight the prevalence of impacted canines in patients who had attended the orthodontic screening clinic at Eastern Riyadh Specialized Dental Center, Kingdom of Saudi Arabia, from January 2014 to December 2016. This was a retrospective study on 507 panoramic radiograph. All panoramic radiographs were taken with standardized equipment and specifications. Frequency and prevalence of the patients were recorded. Total number of males was 203 (40\%) and 304 (60\%) was female. The mean age of the patients was 16.78 years. A total number of 38 (7.5) patients was diagnosed with impacted canine 23 (4.5\%) in females. Impacted canines were seen mostly as unilateral 24 (63.2\%). Left was the most common site of impaction $16(66.7 \%)$.
\end{abstract}

Keywords: canine impaction, maxillary canine.

\section{Introduction}

With the exception of the third molars, impaction of the maxillary permanent canines is the most common form of tooth impaction. ${ }^{(1)}$ An impacted tooth is one that is erupted, partially erupted, or unerupted and will not eventually assume a normal arch relationship with the other teeth and tissues. ${ }^{(2)}$ The eruption of permanent teeth includes series of events, mostly genetically based, whereby tooth germ eruption taking place at a predetermined time and path enables the tooth to find its antagonist at the occlusal plane. As the eruption is a complex process, it is not uncommon that problems may arise, which lead to failure of eruption. ${ }^{(3,4)}$ The most common causes for canine impactions are usually localized and are the result of any one, or combination of the following factors: (a) tooth size-arch length discrepancies, (b) prolonged retention or early loss of the deciduous canine, (c) abnormal position of the tooth bud, (d) the presence of an alveolar cleft, (e) ankylosis, (f) cystic or neoplastic formation, $(\mathrm{g})$ dilaceration of the root, $(\mathrm{h})$ iatrogenic origin and (i) idiopathic condition with no apparent cause. ${ }^{(5,6,7)}$ Relatively recent studies into the frequency with which maxillary canine impaction occurs in the general population have indicated prevalence from $0.27 \%$ in a Japanese population ${ }^{(8)}$ to as much as $2.4 \%$ among Italians, ${ }^{(9)}$ with the condition affecting female patients 2.3 to 3 times more frequently than males. ${ }^{(8,9,10,}$ 11) The aim of the present study was to determine the prevalence of impacted maxillary canine in a sample of patients attending the Orthodontics Clinic at Eastern Riyadh Specialized Dental Center (ERSDC), KSA.

\section{Ii. Materials And Methods}

This retrospective study involved 507 panoramic radiographs of subjects aged 13 to 32 years who had attend the orthodontic screening clinic at Eastern Riyadh Specialized Dental Center, Kingdom of Saudi Arabia, seeking orthodontic treatment from January 2014 to December 2016. All panoramic radiographs were taken with standardized equipment and specifications. The tooth was considered impacted when it was not aligned with the rest of the teeth in either of the dental arches or has no chance to erupt in its position. Data regarding age, sex, number of impacted teeth, arch involved, and type of maxillary canine impaction either unilateral or bilateral from patients records and panoramic radiographs were examined by a single investigator ${ }^{1}$. Data collected was entered into a spreadsheet (Excel 2010) and analyzed subsequently using (SPSS) version 16.0. The prevalence of impacted canine teeth in relation to age, gender and type was assessed and displayed by frequency and percentage. The $p$ value was analyzed by using the Pearson Chi-square test.

\section{Result}

There were total 507 panoramic radiographs subjected for evaluation, among them 203 (40\%) were male and $304(60 \%)$ were female (Table 1, Figure 1). The age ranges from 13 to 32 years with a mean age 16.78 years (Table 2). A total number of impacted maxillary canines were found $38(7.5 \%)$ of which were $15(3 \%)$ in males and $23(4.5 \%)$ in females (Table 3, Figure 2). Unilateral impaction was seen higher in both male and female patients than bilateral impaction with $24(63.2 \%)$ out of 38 case of impaction (9 in males and 15 in 
females) (Table 4, Figure 3). Out of 24 case of unilateral impaction 16 (66.7\%) were in the left side (6 in male, 10 in female) (Table 5).

Table 1. Number and percentage of male and female patients

\begin{tabular}{|c|c|c|}
\hline Gender & No. & Percentage \\
\hline Male & 203 & $40 \%$ \\
\hline Female & 304 & $60 \%$ \\
\hline Total & 507 & $100 \%$ \\
\hline
\end{tabular}

Table 2.Descriptive statistics of age of all sample and mean age of female and

\begin{tabular}{|c|c|c|}
\multicolumn{1}{|c|}{ Gender } & male patient & Std. deviation \\
\hline Male & 16.25 & 3.57 \\
\hline Female & 17.14 & 4.01 \\
\hline Overall & 16.78 & 3.86 \\
\hline
\end{tabular}

Figure 1. Percentage of male and female Patients.

Table 3. Number and percentage of canine impaction in each gender and among all the sample

\begin{tabular}{|c|l|c|c|c|}
\hline \multirow{2}{*}{ Gender } & \multirow{2}{*}{ Criteria } & \multicolumn{2}{|c|}{ Total } \\
\cline { 3 - 5 } & & No impaction & Impaction & \\
\hline \multirow{3}{*}{ Male } & Count & 188 & 15 & 203 \\
\cline { 2 - 5 } & $\%$ gender & $92.6 \%$ & $7.4 \%$ & $100.0 \%$ \\
\cline { 2 - 5 } & $\%$ Total & $37.1 \%$ & $3.0 \%$ & $40.0 \%$ \\
\hline \multirow{3}{*}{ Female } & Count & 281 & 23 & 304 \\
\cline { 2 - 5 } & $\%$ gender & $92.4 \%$ & $7.6 \%$ & $100.0 \%$ \\
\cline { 2 - 5 } & $\%$ Total & $55.4 \%$ & $4.5 \%$ & $60.0 \%$ \\
\hline \multirow{2}{*}{ Total } & Count & 469 & 38 & 507 \\
\cline { 2 - 5 } & $\%$ Total & $92.5 \%$ & $7.5 \%$ & $100.0 \%$ \\
\hline
\end{tabular}

Figure 2. Number and percentage of canine impaction in each gender and among all the sample

Table 4. Number and percentage of unilateral vs bilateral canine impaction and among all sample and within each gender

\begin{tabular}{|c|c|c|c|c|}
\hline \multirow{2}{*}{ Gender } & \multirow{2}{*}{ Criteria } & \multicolumn{2}{|c|}{ Canine impaction } & \multirow{2}{*}{ Total } \\
\cline { 3 - 4 } & & Unilateral & Bilateral & \\
\hline \multirow{3}{*}{ Male } & Count & 9 & 6 & 15 \\
\cline { 2 - 5 } & $\%$ impaction & $60.0 \%$ & $40.0 \%$ & $100.0 \%$ \\
\cline { 2 - 5 } & $\%$ Total & $1.8 \%$ & $1.2 \%$ & $3.0 \%$ \\
\hline \multirow{3}{*}{ Female } & Count & 15 & 8 & 23 \\
\cline { 2 - 5 } & \% impaction & $65.2 \%$ & $34.8 \%$ & $100.0 \%$ \\
\cline { 2 - 5 } & $\%$ of Total & $3.0 \%$ & $1.6 \%$ & $4.5 \%$ \\
\hline \multirow{3}{*}{ Total } & Count & 24 & 14 & 38 \\
\cline { 2 - 5 } & \% impaction & $63.2 \%$ & $36.8 \%$ & $100.0 \%$ \\
\cline { 2 - 5 } & $\%$ of Total & $4.7 \%$ & $2.8 \%$ & $7.5 \%$ \\
\hline
\end{tabular}

Figure 3. Percentage of unilateral Vs bilateral canine impaction and among all sample and within each gender.

\begin{tabular}{|c|c|c|c|c|}
\hline \multicolumn{5}{|c|}{$\begin{array}{l}\text { Table 5. Number and percentage of Right vs Left canine impaction and among all } \\
\text { sample and within each gender }\end{array}$} \\
\hline \multirow[t]{2}{*}{ Gender } & \multirow[t]{2}{*}{ Criteria } & \multicolumn{2}{|c|}{ Canine impaction } & \multirow[t]{2}{*}{ Total } \\
\hline & & Right canine & Left canine & \\
\hline \multirow[t]{3}{*}{ Male } & Count & 3 & 6 & 9 \\
\hline & \%Unilateral & $33.3 \%$ & $66.7 \%$ & $\begin{array}{c}100.0 \\
\%\end{array}$ \\
\hline & $\%$ Total & $0.6 \%$ & $1.2 \%$ & $1.8 \%$ \\
\hline \multirow[t]{3}{*}{ Female } & Count & 5 & 10 & 15 \\
\hline & \%Unilateral & $33.3 \%$ & $66.7 \%$ & $\begin{array}{c}100.0 \\
\%\end{array}$ \\
\hline & $\%$ of Total & $1.0 \%$ & $2.0 \%$ & $3.0 \%$ \\
\hline \multirow[t]{3}{*}{ Total } & Count & 8 & 16 & 24 \\
\hline & \%Unilateral & $33.3 \%$ & $66.7 \%$ & $\begin{array}{c}100.0 \\
\%\end{array}$ \\
\hline & $\%$ of Total & $1.6 \%$ & $3.2 \%$ & $4.7 \%$ \\
\hline
\end{tabular}




\section{Discussion}

Any permanent tooth in the dental arch can be impacted, but the teeth most frequently involved in a descending order are the mandibular and maxillary third molar, the maxillary canines, the mandibular and maxillary second premolar, and maxillary central incisors. ${ }^{(12)}$ Maxillary canines impaction are common finding in orthodontic practices. Many studies have been performed to evaluate their prevalence of impaction.

The present study, conducted to determine the prevalence of impacted maxillary canine in a sample of 507 patients using panoramic radiographs. The data indicated that the prevalence of maxillary canine impaction was more than those reported in other studies. The present study has shown the prevalence of maxillary canine impaction to be $7.5 \%$, which is much higher than the percentage of $3.8 \%$ reported in other study. ${ }^{(13)}$

In this study, the prevalence of unilateral impaction was statistically significant higher $(63.2 \%)$ than bilateral impaction $(36.8 \%) p$ value of 0.002 . This in agreement with a study conducted by Ali Gashi et al which showed that unilateral impaction was more common $(75.6 \%) .{ }^{(14)}$ Left maxillary canine impaction was higher $(66.7 \%)$ than right side impaction (33.3\%) which is consistent with studies conducted by Alrwuili et al and Ali Gashi et al. ${ }^{(13,14)}$ This study shows that females have higher percentage of impaction (7.6\%) than male patient

(7.4\%). Most of studies about impacted maxillary canine; for example Altaee

in her study on patients from Ramadi city in Iraq stated that female: male ratio was 2:1. Sridharan et al., found prevalence of $2.6 \%$ in males and $3.6 \%$ in females. $(15,16,17)$

Early detection, accurate treatment planning and execution are the main stay for these dental conditions. If properly and timely done, might prevent the patient from esthetic and functional discrepancies. A dental surgeon should also have an idea of the prevalence of these dental anomalies among the population he or she is dealing with in dental offices. By doing so, early detection and better treatment results can be achieved which will benefit the patient in long term. ${ }^{(13)}$

\section{Conclusion}

The overall prevalence of impacted maxillary canines is found to be $7.5 \%$ among the selected sample of patients attending orthodontic treatment screening clinic in ERSDC. The occurrence of left maxillary canine impaction is higher than right maxillary canine.

\section{References}

[1]. Adrian Becker and Stella Chaushu. Etiology of maxillary canine impaction: A review. Am J Orthod Dentofacial Orthop 2015;148:557-567.

[2]. $\quad$ Raymond J. Fonseca, Oral and Maxillofacial Surgery volume 1. W.B. Saunders 1st Edition. ISBN 0-7216- 9631-7.

[3]. Sridharan K, Srinivasa H, Madhukar S, Sandbhor S. Prevalence of impacted maxillary canines in patients attending outpatient department of Sri Siddhartha Dental College and hospital of Sri Siddhartha University, Tumkur, Karnataka. J Dent Sci Res 2010; 1:109-17.

[4]. Thilander B, Jakobsson SO. Local factors in impaction of maxillary canines. Acta Odontol Scand 1968; 26:145-68.

[5]. Adrian Becker, The Orthodontic Treatment of Impacted Teeth (Ed 2), published by Martin Dunitz Ltd 1998.

[6]. Becker A, Palatal canine displacement: guidance theory or an anomaly of genetic origin? Angle Orthod. 1995; 65 : 95-8.

[7]. Jacoby H. The etiology of maxillary canine impactions. Am J Orthod. 1983;84(2):125-32.

[8]. Takahama Y, Aiyama Y. Maxillary canine impaction as a possible microform of cleft lip and palate. Eur J Orthod 1982;4:275-7.

[9]. SacerdotiR,BaccettiT.Dentoskeletalfeaturesassociatedwithuni- lateral or bilateral palatal displacement of maxillary canines. Angle Orthod 2004;74:725-32

[10]. Oliver RG, Mannion JE, Robinson JM. Morphology of the maxillary lateral incisor in cases of unilateral impaction of the maxillary canine. Br J Orthod 1989;16:9-16.

[11]. Becker A, Smith P, Behar R. The incidence of anomalous maxillary lateral incisors in relation to palatally-displaced cuspids. Angle Orthod 1981;51:24-9.

[12]. Wafa Al-Faleh,Completely Impacted teeth in dentate and edentulous Jaws, Pakistan Oral \& Dental Journal 2009;29: 255-260

[13]. Mohammad Raji Alrwuili et al, Prevalence and localization of impacted canine among al-qurayyat orthodontic patients: a study conducted over the period of 4 years, Pakistan Oral \& Dental Journal vol 36, no. 1 January-march 2016; 75-78

[14]. Gashi A, Kamberi B, Abdyli RA, et al. The incidence of impacted maxillary canines in a Kosovar population. Inter Schol Research Notices 2014; 1-4.

[15]. Altaee ZH. Incidence of impacted maxillary canine and associated with maxillary lateral incisor anomalies in Ramadi city. Asian J Sci and Technol 2014; 5(3): 226-9.

[16]. Sridharan K, Srinivasa H, Madhukar S, Sandbhor S. Prevalence of impacted maxillary canines in patients attending outpatient department of Sri Siddhartha Dental College and hospital of Sri Siddhartha University, Tumkur, Karnataka. J Dent Sci Res 2010; 1:109-17.

[17]. Aqeel Ibrahim Lazim, The Prevalence of Impacted Maxillary Canine among Iraqi Patients of Al-Basrah City. J Bagh College Dentistry,Vol. 28( 1), M arch 2016; 73-77. 